\title{
Research for reducing the Minimum Miscible Pressure of crude oil and carbon dioxide by injecting citric acid isobutyl ester
}

\author{
Guangjuan $\mathrm{Fan}^{3,}$, Yuejun Zhao ${ }^{1,2}$, Yilin $\mathrm{Li}^{1}$, Xiaodan Zhang ${ }^{1}$, and Hao Chen ${ }^{1}$ \\ ${ }^{1}$ Department of Petroleum Engineering, Northeast Petroleum University, Daqing 163318, China \\ ${ }^{2}$ Key Laboratory of Enhanced Oil Recovery (Northeast Petroleum University), Ministry of Education, Daqing 163318, China \\ ${ }^{3}$ School of Earth Sciences, Northeast Petroleum University, Daqing 163318, China
}

Received: 14 October 2020 / Accepted: 24 February 2021

\begin{abstract}
Carbon dioxide miscible flooding has become one of the important technologies for improving oil recovery. The Minimum Miscible Pressure (MMP) is the key parameter to realize miscible flooding. As the MMP in the research area is higher than the formation fracture pressure, miscible flooding cannot be formed. To address this problem, it is necessary to find a way to reduce the MMP. Citric acid isobutyl ester is chosen to reduce the MMP of carbon dioxide and crude oil in this research. The effect of citric acid isobutyl ester on reducing the MMP was measured by the method of long-slim-tube displacement experiment. The experiment results show that the MMP is 29.6 MPa and can be obviously reduced by injecting the slug of citric acid isobutyl ester. The MMP could decrease gradually with constantly adding the injected slug of citric acid isobutyl ester, but the decrease becomes smaller and smaller. The optimum injected slug size of the chemical reagent is $0.003 \mathrm{PV}$. Under the condition of the slug size, the MMP is reduced to 23.5 MPa and the reduction is 6.1 MPa.
\end{abstract}

\section{Introduction}

There are lots of successful cases by injecting carbon dioxide $\left(\mathrm{CO}_{2}\right)$ to improve oil recovery in America, Russia, Canada, China, and so on. The carbon dioxide injection technology has become an Enhanced Oil Recovery (EOR) technology that is widely applied in the world [1-5]. It is more suitable for most low permeability oil fields to be developed by gas injection [6-9]. Carbon dioxide injection has the advantages of wide application, low cost, significantly improved oil recovery [10-12]. At the same time, carbon dioxide flooding can solve the problem of carbon dioxide sequestration to a certain extent, reduce greenhouse gas emissions into the atmosphere, and alleviate the pressure of the environmental pollution [13-18]. So under the background of energy shortage, energy conservation and emission reduction, carbon dioxide flooding has a broad application prospect [19-23]. Indoor experiment and field test show that the effect of carbon dioxide miscible flooding to improve oil recovery is better from light to intermediate viscosity crude oils than that of immiscible flooding [24-28]. However, miscible flooding cannot be fully realized in some oil field blocks if the Minimum Miscible Pressure (MMP) is higher than the reservoir pressure [29, 30]. To address this problem, it is necessary to find a way to reduce the MMP.

\footnotetext{
* Corresponding author: 1259248282@qq.com
}

The following are the main methods to reduce the MMP of $\mathrm{CO}_{2}$ flooding at home and abroad [31, 32].

Low-molecular-weight non-ionic surfactant method: Guo et al. selected CAE and CAF as non-ionic surfactants to reduce the MMP, and investigated the oil solubility, solubility in supercritical $\mathrm{CO}_{2}$ and viscosity reduction of the two reagents. The results show that such surfactants can reduce the MMP [33].

Miscible solvent method: In this method, the miscible solvent is injected into the ground and diffused in the formation to dissolve with the crude oil to form a miscible displacement zone; the injected $\mathrm{CO}_{2}$ gas comes into contact with the miscible zone to achieve miscibility at low pressure, so as to improve the oil recovery $[34,35]$. Zhang et al. carried out a large number of experiments on singlecomponent methanol, ethanol, n-hexane, n-octane, and multi-component petroleum ether, light oil and other miscible solvents [34]. Peng et al. injected a certain ratio of liquefied gas into $\mathrm{CO}_{2}$ to study its influence on the miscible pressure of $\mathrm{CO}_{2}$ flooding [35].

$\mathrm{CO}_{2}$-philic non-ionic surfactant method: Such surfactants proposed in domestic and foreign literature are mainly siloxanes and fluorides [36-38]. Due to the high solubility in $\mathrm{CO}_{2}$, the fluoride surfactant has good affinity with $\mathrm{CO}_{2}$. For example, the Perfluoroalkylpolyether (PEPE) surfactant $[39,40]$, which can reduce the surface tension between $\mathrm{CO}_{2}$ and water to a very low level, is the most effective $\mathrm{CO}_{2}$-philic surfactant at present. Hoefling and other scholars discovered 
that PEPE has better solubility in supercritical $\mathrm{CO}_{2}[41]$. DeSimone and Keiper found that polyacrylic acid 1, 1-dihydro-Perfluorooctanoic Acid (PFOA) has strong $\mathrm{CO}_{2}$-philic performance, then synthesized the block polymer surfactant of PFOA and Polystyrene (PS), and developed the supercritical $\mathrm{CO}_{2}$ cleaning technology [42].

Supercritical $\mathrm{CO}_{2}$ microemulsion method: In this method, the MMP is reduced by using the surfactant dissolved in supercritical $\mathrm{CO}_{2}$ to form nanoscale aggregates $[43,44]$. Both the supercritical and microemulsion technologies are needed for the supercritical $\mathrm{CO}_{2}$ microemulsion technology to reduce the miscible pressure of $\mathrm{CO}_{2}$ flooding. Dong and other scholars obtained the supercritical $\mathrm{CO}_{2}$ microemulsion using the Di-(2-ethylhexyl) sodium sulfosuccinate (AOT) as surfactant, ethanol as auxiliary, and the MMP between supercritical $\mathrm{CO}_{2}$ microemulsion and alkane was investigated, including alkane carbon number, temperature, surfactant addition and other factors [44]. Dong et al. studied the MMP between supercritical $\mathrm{CO}_{2}$ microemulsion and Daqing heavy oil [45].

According to the carbon dioxide pilot test results of the research area, the gas injection can realize stable injection with low pressure, which solves the problems of water flooding difficulty of the ultra-low permeability reservoir. Producing wells got the apparent effect and higher production levels in the case of gas injection. However, the overall oil production speed is slow. According to the result of longslim-tube displacement experiment, the MMP of the research area is $29.6 \mathrm{MPa}$ that is higher than the reservoir pressure, so that the research area cannot form the miscible flooding as a whole $[46,47]$. Therefore, the research for reducing the MMP of carbon dioxide miscible flooding can carve out a new way for comprehensive realization of miscible flooding to significantly improve oil recovery in research area [48]. Citric acid isobutyl ester is chosen to reduce the MMP of carbon dioxide and crude oil of research area in this research [49].

\section{Determination of the MMP}

\subsection{Experimental material for determining the MMP}

The crude oil used in the experiment is the simulated crude oil prepared by the surface oil and natural gas in the research area according to the formation conditions and fluid characteristics. The experiment temperature is $108.5^{\circ} \mathrm{C}$. The viscosity of crude oil is $1.88 \mathrm{mPa} \mathrm{s}$ at $108.5^{\circ} \mathrm{C}$ and $23.8 \mathrm{MPa}$ that are the temperature and the pressure of the formation. The molecular weight of $\mathrm{C}_{7+}$ in crude oil composition is $347.29 \mathrm{~g} / \mathrm{mol}$, and the density of $\mathrm{C}_{7+}$ is $0.8971 \mathrm{~g} / \mathrm{cm}^{3}$. The purity of carbon dioxide gas is $99.9 \%$, and the properties are exactly the same as that of carbon dioxide injected in the research area.

\subsection{Experimental apparatus for determining the MMP}

The experimental apparatuses mainly include: the piston container of carbon dioxide, the piston container of simulated crude oil, the piston container of formation water, slim tube filled with quartz sand particles, liquid flowmeter, gas

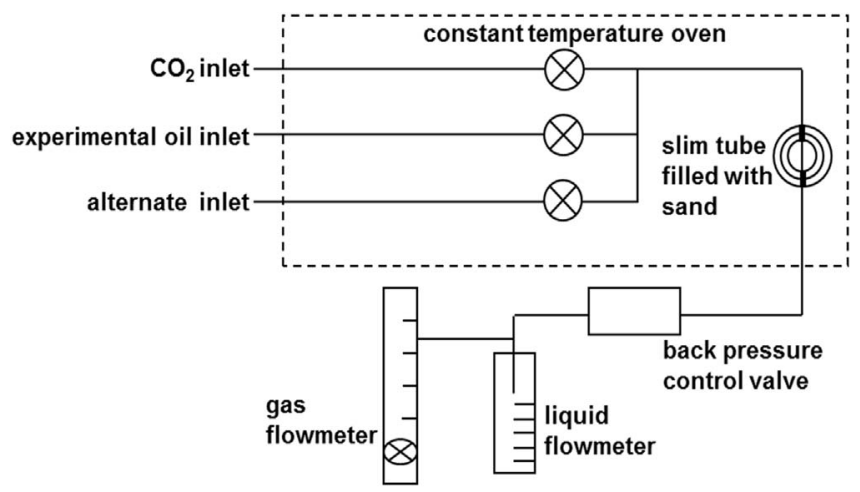

Fig. 1. The sketch of long-slim-tube displacement experimental apparatus.

flowmeter, back pressure control valve. The sketch of experimental apparatus and flow chart are shown in Figure 1. The photos of long-slim-tube displacement experimental apparatus are shown in Figure 2.

The injection pump is $I S C O$ full automatic pump, which is manufactured by Teledyne ISCO Corporation of American. The working pressure range is $0-70 \mathrm{MPa}$ and the accuracy is $0.01 \mathrm{~mL}$. The working pressure range of back pressure control valve is $-70 \mathrm{MPa}$. The highest temperature of constant temperature box is $200{ }^{\circ} \mathrm{C}$. The accuracy of gas flowmeter is $1 \mathrm{~mL}$. The long slim tube is a one-dimensional artificial porous medium spiral stainless steel coil tightly filled with approximately 200 mesh of pure quartz sand. The experimental parameters are shown in Table 1.

\subsection{Preparation of the formation oil sample}

Indoor experiment formation oil is prepared with ground oil and natural gas. The process is to put a certain amount of ground oil into the high pressure physical instrument PVT barrel, seal it and heat it up to the formation temperature, then put the gas into the PVT barrel at the saturation pressure, stir and increase pressure to the formation pressure, measure the saturation pressure of crude oil and the dissolved gas-oil ratio. If the saturation pressure and the actual formation oil saturation pressure are not equal, we should adjust the amount of dissolved gas in the PVT barrel until the saturation pressure and gas-oil ratio measured are equal to that of the formation oil.

\subsection{The experimental process of determining the MMP}

The methods of predicting the MMP generally include laboratory experiment and theoretical calculation [50-54]. Laboratory experiment methods include long-slim-tube displacement experiment method, interfacial tension method, Rising Bubble Apparatus (RBA) method and vapor density method. Theoretical calculation methods include empirical formula method, equation of state method $[55,56]$ and simulation calculation method. Among all the prediction methods, the long-slim-tube displacement experiment method has been widely used and recognized by researchers and 

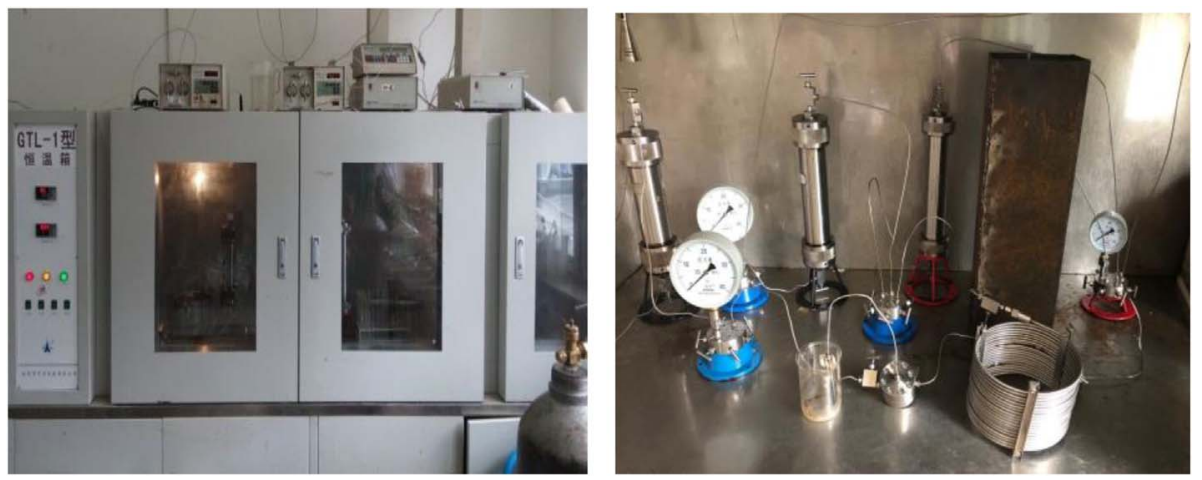

Fig. 2. The photos of long-slim-tube displacement experimental apparatus.

Table 1. Basic parameters of the long-slim-tube displacement experimental model.

\begin{tabular}{lc}
\hline Main parameters & $\begin{array}{c}\text { Numerical } \\
\text { values }\end{array}$ \\
\hline Maximum pressure $(\mathrm{MPa})$ & 70 \\
Maximum temperature $\left({ }^{\circ} \mathrm{C}\right)$ & 200 \\
Length $(\mathrm{cm})$ & 2000 \\
Outer diameter $(\mathrm{cm})$ & 0.637 \\
Inner diameter $(\mathrm{cm})$ & 0.387 \\
Filler (pure quartz sand) (mesh) & $185-230$ \\
Permeability measured with water $\left(\mu \mathrm{m}^{2}\right)$ & 2.93 \\
Porosity $(\%)$ & 43.26 \\
\hline
\end{tabular}

scholars. The long-slim-tube displacement experiment is repeatable. Compared with other methods, this method is more in line with the characteristics of oil and gas displacement process in the porous medium of crude oil reservoir. Moreover, the influence of unfavorable factors such as heterogeneity, mobility ratio, viscous fingering and gravity separation of lithology can be eliminated to the greatest extent [57-59]. Therefore, the long-slim-tube displacement experiment method was used to determine the MMP in the research area.

\section{(1) Experiment preparation}

Temperature setting: Turn on the power switch of the constant temperature box and heat up. When the temperature is close to the formation temperature, start the constant temperature controller. After $3 \mathrm{~h}$, the temperature can be completely maintained at the predetermined value.

Tube cleaning: Saturate the slim tube model adequately with petroleum ether, and use high pressure air to blow dry the petroleum ether.

Import carbon dioxide: Open the pump and push the piston back to the top of the piston container to vent the gas from the container; inject the displacing gas carbon dioxide into the piston container and close the valve.

The long slim tube should be vacuumized. Then saturate the formation water into the sand filling slim tube and calculate the porosity.
Clean the formation water in the sand filling slim tube with toluene. Dry it in a thermostat to evaporate the toluene.

Saturate the simulated oil into the sand filling slim tube. Inject the simulated oil into the slim tube model with the ISCO constant-pressure and constant-speed pump. Stop the injection when the 1.5 PV simulated oil is injected. The injection and output of simulated oil are calculated. The amount of saturated oil injected into the tube is determined according to the volume difference. Then close the process and prepare for a displacement experiment.

(2) Start the ISCO constant-pressure and constantspeed pump to increase the pressure of gas in the piston container, and make it 1 3 MPa lower than the displacement pressure.

(3) Raise the back pressure to the predetermined displacement pressure through a manual pump.

(4) Open the pump to inject carbon dioxide under constant pressure, open the slim tube outlet valve, and adjust the gas pressure to make it equal to or slightly higher than the displacement pressure.

(5) In the process of displacement, determine oil production, gas volume and pump reading regularly as required, and check oil sample saturation. When the cumulative volume of the gas drive is greater than $1.2 \mathrm{PV}$, the displacement is stopped and the recovery under this pressure is calculated.

(6) At the end of the displacement process, the cleaning process is started, and the petroleum ether is directly injected into the slim tube model, and the appropriate back pressure is maintained. The flow rate of petroleum ether in the slim tube is not too fast, so as not to affect the cleaning effect. Close the outlet for 1-2 h, and make the petroleum ether and residual oil fully contact each other under high pressure. Dissolve the residual oil in the petroleum ether, and release it from the outlet. Repeatedly, the mixture of petroleum ether and residual oil is discharged. When the mixture and the component of pure petroleum ether are basically the same, the residual oil in the model is determined to be completely removed and fully saturated with petroleum ether. Then, high-pressure air is injected from the inlet, and the remaining petroleum ether in the slim tube is blown into the oil-gas separator, and the pipeline is blown dry for the next experiment. 
Table 2. The long-slim-tube displacement experiment results of crude oil for injecting $\mathrm{CO}_{2}$.

\begin{tabular}{lccc}
\hline $\begin{array}{l}\text { Experimental temperature } \\
\left({ }^{\circ} \mathrm{C}\right)\end{array}$ & $\begin{array}{c}\text { Experimental pressure } \\
(\mathrm{MPa})\end{array}$ & $\begin{array}{c}\text { Recovery at } 1.2 \mathrm{PV} \\
(\%)\end{array}$ & $\begin{array}{c}\text { Miscible evaluation } \\
108.5\end{array} 2^{20}$ \\
108.5 & 25 & 69.90 & Immiscible \\
108.5 & 30 & 80.35 & Immiscible \\
108.5 & 35 & 90.15 & Miscible \\
108.5 & 40 & 90.50 & Miscible \\
108.5 & 45 & 91.22 & Miscible \\
\hline
\end{tabular}

(7) Follow the above steps for displacement at the next pressure point.

In general, the MMP can be analyzed by measuring the recovery at more than 5 pressure points. The experimental back pressures in experiment are $20 \mathrm{MPa}, 25 \mathrm{MPa}, 30 \mathrm{MPa}$, $35 \mathrm{MPa}, 40 \mathrm{MPa}$ and $45 \mathrm{MPa}$. Then the MMP is calculated according to the relationship between the oil recovery and the experimental displacement pressure.

\subsection{Experimental result}

According to the experimental results, the recovery of carbon dioxide flooding under different experimental pressures can be obtained (Tab. 2).

The generally accepted criterion for miscible flooding is that the oil recovery is greater than $90 \%$ when $1.2 \mathrm{PV}$ is injected, and the displacement efficiency does not increase significantly with the increase of displacement pressure [60-63]. In Table 2, the recovery corresponding to the experimental pressure at $20 \mathrm{MPa}$ and $25 \mathrm{MPa}$ is lower than $90 \%$, so the carbon dioxide flooding under these pressures is in the immiscible flooding stage, and the recovery corresponding to the experimental pressure above $30 \mathrm{MPa}$ is higher than $90 \%$, so the carbon dioxide flooding with the pressure above $30 \mathrm{MPa}$ can form miscible flooding. According to the experimental results in Table 2, the relation curve between the oil recovery and the experimental displacement pressure when 1.2 PV carbon dioxide is injected is plotted (Fig. 3). It can be seen from the figure that the MMP of the reservoir crude oil and the carbon dioxide system in the research area predicted by the long-slim-tube displacement experiment method is $29.6 \mathrm{MPa}$.

\section{Injection slug size optimization of citric acid isobutyl ester}

\subsection{Experimental material and experimental apparatus}

Experimental material: The crude oil used in the experiment is the simulated crude oil prepared by the surface oil and natural gas in the research area according to the formation conditions and fluid characteristics. The experiment temperature is $108.5^{\circ} \mathrm{C}$. The purity of carbon dioxide gas is $99.9 \%$, and the property of carbon dioxide gas injected into the research area is exactly the same. Citric acid isobutyl ester is prepared from Section 3.2.

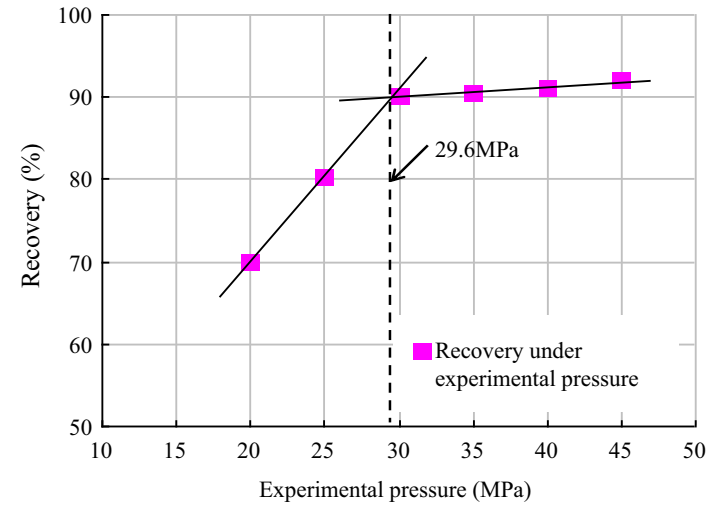

Fig. 3. The relation curve of recovery and displacement pressure.

Experimental apparatus: The apparatus for this experiment is the same as that for measuring the MMP of crude oil and carbon dioxide by the long-slim-tube method, as shown in Figure 1.

\subsection{Preparation of citric acid isobutyl ester}

Citric acid isobutyl ester is oil-soluble surfactant, which is insoluble in water, but can be mutually soluble with mineral oil, castor oil, alcohol and other organic solvents. It is nontoxic, tasteless, low volatile, heat and light resistant, bacteria-resistant, non-bacterial, non-irritating, flame retardant and degradable. As environmentally friendly reagent, the oil-soluble surfactant can not only dissolve in crude oil to reduce viscosity, but also dissolve in carbon dioxide to reduce the interfacial tension between crude oil and carbon dioxide, thus reducing the MMP between crude oil and carbon dioxide. The chemical reagent is prepared by the reaction of citric acid and corresponding alcohols under the condition of catalyst. The following is the synthesis process of citric acid isobutyl ester.

\subsubsection{Experimental material and apparatus of preparing citric acid isobutyl ester}

Main experimental materials: citric acid, isobutyl alcohol, p-toluene sulfonic acid, anhydrous sodium sulfate, sodium bicarbonate, sodium chloride, and so on.

Main experimental apparatuses: round-bottom flask, upper water separator, reflux condensing tube and separating funnel, and so on. 


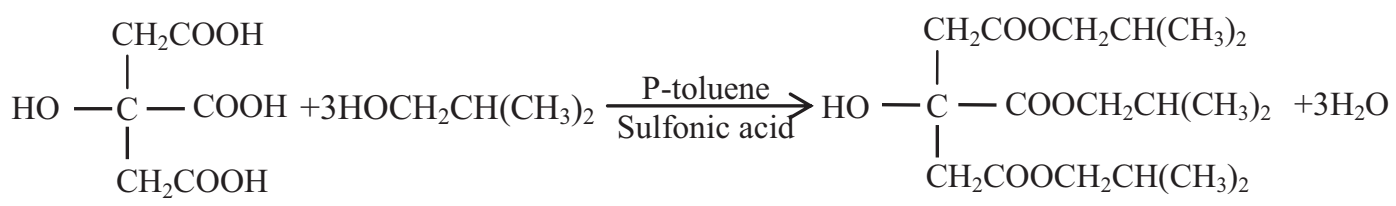

Fig. 4. The chemical reaction equation of citric acid and isobutyl alcohol.

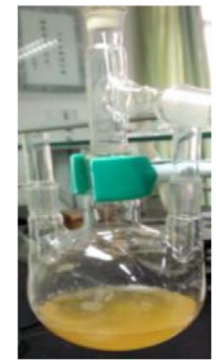

Fig. 5. The citric acid isobutyl ester obtained after distillation.

\subsubsection{Experimental process of preparing citric acid isobutyl ester}

1. Adding chemicals: Add excessive citric acid and isobutyl alcohol to the round-bottom flask.

2. Adding catalyst: Heat the reaction mixture to $95{ }^{\circ} \mathrm{C}$ while stirring, add p-toluene sulfonic acid into the mixture after citric acid is dissolved.

3. Heating: Heat to $110{ }^{\circ} \mathrm{C}$. The water produced is discharged through the manifold. The reaction begins when water is discharged from the condensing tube. The reaction ends when the condensing tube stops discharging water. P-toluene sulfonic acid as a catalyst can be used for a long time. The chemical reaction equation of citric acid and isobutyl alcohol is shown in Figure 4.

4. Filtration: After the reaction is cooled, filter out the catalyst, which can be washed and dried for reuse.

5. Filter out citric acid: Add saturated sodium bicarbonate solution and saturated sodium chloride solution. The mixture is separated with the separatory funnel when the temperature reduces to $25^{\circ} \mathrm{C}$.

6. Water removal: The organic layer is filtered with anhydrous sodium sulfate.

7. Distillation: Heat to $131.2^{\circ} \mathrm{C}$. After isobutyl alcohol is evaporated, we get citric acid isobutyl ester. The citric acid isobutyl ester obtained after distillation is shown in Figure 5.

\subsection{Experimental process of optimizing injection slug size}

For the procedure of this experiment, refer to that of measuring the MMP of crude oil and carbon dioxide with the long-slim-tube method. The difference is that citric acid isobutyl ester is injected before injecting $\mathrm{CO}_{2}$ for displacement.

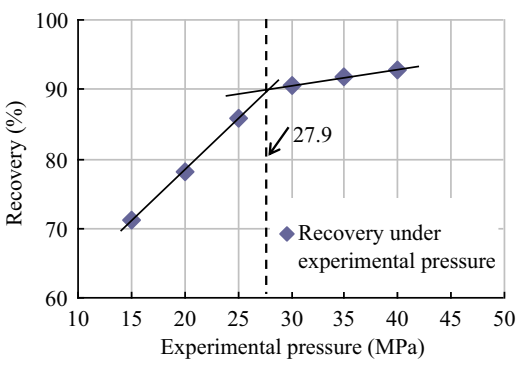

Fig. 6. Relationship diagram between pressure and recovery at 0.001 PV slug size.

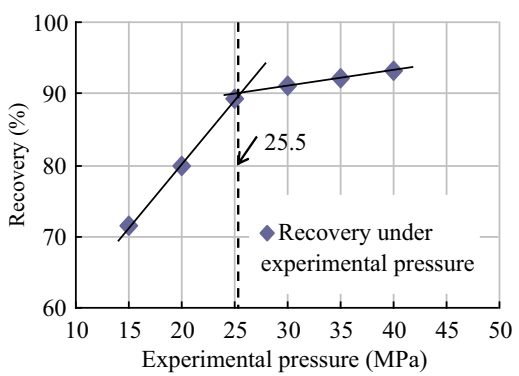

Fig. 7. Relationship diagram between pressure and recovery at 0.002 PV slug size.

The slug sizes of citric acid isobutyl ester are $0.001 \mathrm{PV}$, $0.002 \mathrm{PV}, 0.003 \mathrm{PV}, 0.004 \mathrm{PV}$, respectively. The recoveries under different pressures were measured after citric acid isobutyl ester was injected with different slug sizes. Then the MMP was calculated for different slug sizes, and the optimal slug size was determined according to the relationship between the slug size and the MMP.

\subsection{The results after the injection of citric acid isobutyl ester slug}

1. The experimental results of the MMP when the injected citric acid isobutyl ester slug size is $0.001 \mathrm{PV}$ are shown in Figure 6.

2. The experimental results of the MMP when the injected isobutyl citrate slug size is $0.002 \mathrm{PV}$ are shown in Figure 7.

3. The experimental results of the MMP when the injected isobutyl citrate slug size is $0.003 \mathrm{PV}$ are shown in Figure 8.

4. The experimental results of the MMP when the injected isobutyl citrate slug size is $0.004 \mathrm{PV}$ are shown in Figure 9. 


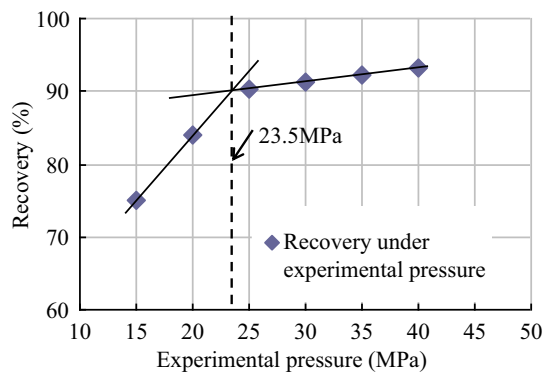

Fig. 8. Relationship diagram between pressure and recovery at 0.003 PV slug size.

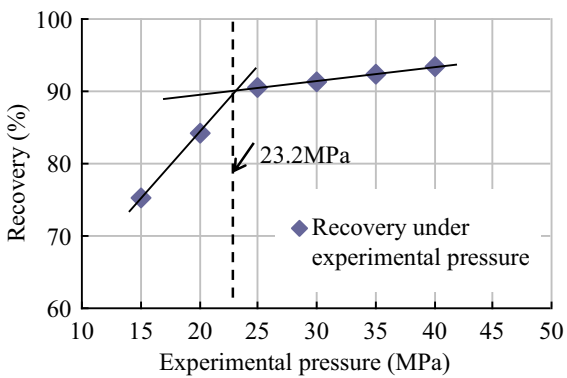

Fig. 9. Relationship diagram between pressure and recovery at 0.004 PV slug size.

Table 3. Relationship chart between the MMP and the slug size of citric acid isobutyl ester.

\begin{tabular}{lcccc}
\hline The slug size & $0.001 \mathrm{PV}$ & $0.002 \mathrm{PV}$ & $0.003 \mathrm{PV}$ & $0.004 \mathrm{PV}$ \\
MMP (MPa) & 27.9 & 25.5 & 23.5 & 23.2 \\
\hline
\end{tabular}

As seen from Figures 6 to 9, when citric acid isobutyl ester with slug sizes of $0.001 \mathrm{PV}, 0.002 \mathrm{PV}, 0.003 \mathrm{PV}$ and $0.004 \mathrm{PV}$ is injected, the MMPs of crude oil and carbon dioxide measured are 27.9 MPa, 25.5 MPa, 23.5 MPa and 23.2 MPa. From this, we can obtain the relationship between the slug size of citric acid isobutyl ester and the MMP (Tab. 3 and Fig. 10).

As seen from Figure 10, the MMP of crude oil and carbon dioxide measured gradually decreases with the increase of the injected slug of citric acid isobutyl ester, but the decrease becomes smaller and smaller. The optimal injected slug size of citric acid isobutyl ester is $0.003 \mathrm{PV}$. In this case, the MMP measured is $23.5 \mathrm{MPa}$. Compared with the MMP 29.6 MPa when citric acid isobutyl ester is not injected, the reduction is $6.1 \mathrm{MPa}$.

\section{Conclusion}

The minimum miscibility pressure of crude oil and carbon dioxide system in the research area determined by the long-slim-tube displacement experiment is 29.6 MPa. The MMP measured schemes for injection of citric acid isobutyl ester with different slug sizes are established and completed.

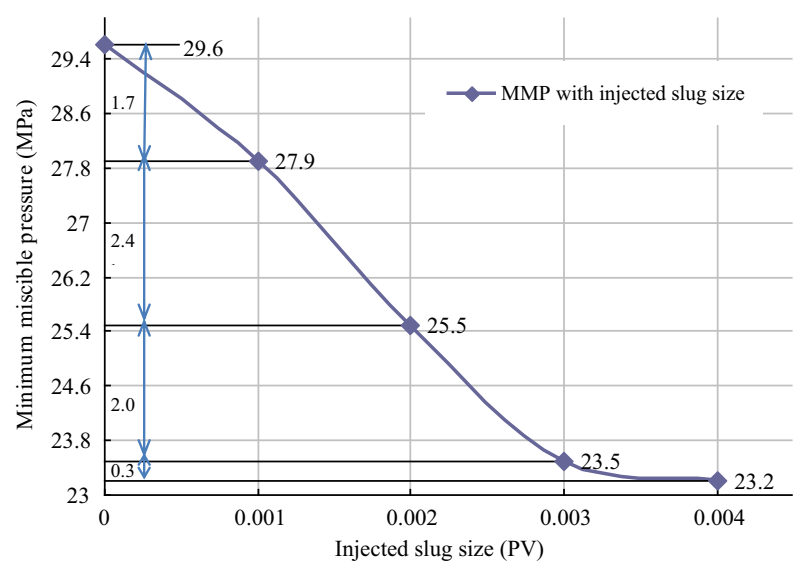

Fig. 10. Relationship diagram between the MMP and the injected slug size of citric acid isobutyl ester.

The experimental results show that with the increase of the injected slug size of citric acid isobutyl ester, the measured MMP gradually decreases, but the decrease becomes smaller and smaller. The optimal size of the injected slug is $0.003 \mathrm{PV}$. Under the condition of the slug size, the MMP measured after the addition of citric acid isobutyl ester slug is $23.5 \mathrm{MPa}$, which decreases by $6.1 \mathrm{MPa}$ compared with 29.6 $\mathrm{MPa}$ when the slug is not injected. The injection of citric acid isobutyl ester slug can significantly reduce the MMP.

\section{Conflicts of interest}

There are no conflicts of interest to declare.

Acknowledgments. This work was financially supported by the National Natural Science Foundation of China (42002154, $51834005)$, the Natural Science Foundation of Heilongjiang Province (E2016008, QC2016055), the PetroChina Innovation Foundation (2020D-5007-0213), the Youths Science Foundation of Northeast Petroleum University (2019QNL-15) and Open Fund Project of Heilongjiang Key Laboratory of Oil and Gas Reservoir Formation Mechanism and Resource Evaluation (KL20190101). The authors would like to thank the editor and the reviewers of this paper for their valuable comments that helped improve the quality of the paper.

\section{References}

1 Azizkhani A., Gandomkar A. (2020) A novel method for application of nanoparticles as direct asphaltene inhibitors during miscible $\mathrm{CO}_{2}$ injection, J. Petrol. Sci. Eng. 185, 106661. https://doi.org/10.1016/j.petrol.2019.106661.

2 Mogensen K. (2016) A novel protocol for estimation of minimum miscibility pressure from slimtube experiments, $J$. Petrol. Sci. Eng. 146, 545-551. https://doi.org/10.1016/j. petrol.2016.07.013.

3 Oschatz M., Antonietti M. (2018) A search for selectivity to enable $\mathrm{CO}_{2}$ capture with porous adsorbents, Energy Environ. Sci. 11, 57-70. 
4 Zhou N., Khanna N., Feng W. (2018) Scenarios of energy efficiency and $\mathrm{CO}_{2}$ emissions reduction potential in the buildings sector in China to year 2050, Nat. Energy 3, 978-984.

5 Kolster C., Masnadi M.S., Krevor S., Dowell N.M., Brandt A.R. (2017) $\mathrm{CO}_{2}$ enhanced oil recovery: A catalyst for gigatonne-scale carbon capture and storage deployment? Energy Environ. Sci. 10, 2594-2608.

6 Jalilov A.S., Li Y., Kittrell C. (2017) Increased $\mathrm{CO}_{2}$ selectivity of asphalt-derived porous carbon through introduction of water into pore space, Nat. Energy 2, 932-938.

7 Chen G.Y., Gao H.X., Fu K.Y., Zhang H.Y., Liang Zh.W., Tontiwachwuthikul A. (2020) An improved correlation to determine minimum miscibility pressure of $\mathrm{CO}_{2}-$ oil system, Green Energy Environ. 5, 97-104.

8 Xing W., Liu Ch., Zhou Z.Y., Zhang L., Zhou J., Zhuo Sh.P., Yan Z.F., Gao H., Wang G.Q., Qiao Sh.Zh. (2012) Superior $\mathrm{CO}_{2}$ uptake of N-doped activated carbon through hydrogenbonding interaction, Energy Environ. Sci. 5, 7323-7327.

9 Birdja Y.Y., Pérez-Gallent E., Figueiredo M.C. (2019) Advances and challenges in understanding the electrocatalytic conversion of carbon dioxide to fuels, Nat. Energy 4, 732-745.

10 Ahmadi M.A., Zendehboudi S., James L.A. (2017) A reliable strategy to calculate minimum miscibility pressure of $\mathrm{CO}_{2}$-oil system in miscible gas flooding processes, Fuel 208, 117-126.

11 Zhang A.G., Fan Z.F., Zhao L. (2020) An investigation on phase behaviors and displacement mechanisms of gas injection in gas condensate reservoir, Fuel 268, 117373. https://doi.org/10.1016/j.fuel.2020.117373.

12 Mutailipu M., Jiang L.L., Liu X.J., Liu Y., Zhao J.F. (2019) $\mathrm{CO}_{2}$ and alkane minimum miscible pressure estimation by the extrapolation of interfacial tension, Fluid Phase Equilibr. 494, 103-114.

13 Gong H.J., Qin X.J., Shang Sh.X., Zhu Ch.F., Xu L., San Q., Li Y.J., Dong M.Zh. (2020) Enhanced shale oil recovery by the Huff and Puff Method using $\mathrm{CO}_{2}$ and cosolvent mixed fluids, Energy Fuels 34, 1438-1446.

14 Ghorbani M., Gandomkar A., Montazeri G. (2019) Describing a strategy to estimate the $\mathrm{CO}_{2}$-heavy oil minimum miscibility pressure based on the experimental methods, Energ. Source. Part A 41, 17, 2083-2093.

15 Yu H.Y., Lu X., Fu W.R., Wang Y.Q., Xu H., Xie Q.Ch., $\mathrm{Qu}$ X.F., Lu J. (2020) Determination of minimum near miscible pressure region during $\mathrm{CO}_{2}$ and associated gas injection for tight oil reservoir in Ordos Basin, China, Fuel 263, 116737. https://doi.org/10.1016/j.fuel.2019.116737.

$16 \mathrm{Wu}$ Sh.Y., Li Zh.M., Sarma H.K. (2020) Influence of confinement effect on recovery mechanisms of $\mathrm{CO}_{2}$-enhanced tight-oil recovery process considering critical properties shift, capillarity and adsorption, Fuel 262, 116569. https://doi. org/10.1016/j.fuel.2019.116569.

17 Shao Y., Luo Ch., Deng B.W., Yin B., Yang M.B. (2020) Flexible porous silicone rubber-nanofiber nanocomposites generated by supercritical carbon dioxide foaming for harvesting mechanical energy, Nano Energy 67, 104290. https://doi.org/10.1016/j.nanoen.2019.104290.

18 Koornneef J., Ramírez A., Turkenburg W., Faaij A. (2012) The environmental impact and risk assessment of $\mathrm{CO}_{2}$ capture, transport and storage - An evaluation of the knowledge base, Progr. Energy Combust. Sci. 38, 62-86.

19 Kaufmann R.K., Connelly C. (2020) Oil price regimes and their role in price diversions from market fundamentals, Nat. Energy 5, 141-149. https://doi.org/10.1038/s41560-020-0549-1.
20 Zhang J., Zhang H.X., Ma L.Y., Liu Y., Zhang L. (2020) Performance evaluation and mechanism with different $\mathrm{CO}_{2}$ flooding modes in tight oil reservoir with fractures, J. Petrol. Sci. Eng. 188, 106950. https://doi.org/10.1016/j.petrol. 2020.106950.

21 Yang Z.H., Wu W., Dong Zh.X., Lin M.Q., Zhang Sh.W., Zhang J. (2019) Reducing the minimum miscibility pressure of $\mathrm{CO}_{2}$ and crude oil using alcohols, Colloids Surf. A Physicochem. Eng. Aspects 568, 105-112.

22 Torabi F., Qazvini F.A., Kavousi A. (2012) Comparative evaluation of immiscible, near miscible and miscible $\mathrm{CO}_{2}$ huff-n-puff to enhance oil recovery from a single matrixfracture system (experimental and simulation studies), Fuel 93, 4, 443-453.

23 Guo P., Hu Y.Sh., Qin J.Sh., Li Sh., Jiao S.J., Chen F., He J. (2017) Use of oil-soluble surfactant to reduce minimum miscibility pressure, Petrol. Sci. Technol. 35, 4, 345-350.

24 Ju B.Sh., Qin J.Sh., Li Zh.P. (2012) A prediction model for the minimum miscibility pressure of the $\mathrm{CO}_{2}$-crude oil system, Acta Petrolei Sinica 33, 2, 274-277.

25 Qin J.Sh., Han H.Sh., Liu X.L. (2015) Application and enlightenment of carbon dioxide flooding in the United States of America, Petrol. Explor. Dev. 42, 2, 209-216.

26 Hawthorne B.S., Miller D.J., Gorecki C.D. (2014) A rapid method for determining $\mathrm{CO}_{2}$ /oil MMP and visual observations of $\mathrm{CO}_{2}$ /oil interactions at reservoir conditions, Energy Proc. 63, 7724-7731.

27 Ma M., Liu K., Shen J., Kas R., Smith W.A. (2018) In Situ fabrication and reactivation of highly selective and stable $\mathrm{Ag}$ catalysts for electrochemical $\mathrm{CO}_{2}$ conversion, ACS Energy Lett. 3, 1301-1306.

28 Moghaddam A.K., Dehaghani A.H.S. (2017) Modeling of asphaltene precipitation in calculation of minimum miscibility pressure, Ind. Eng. Chem. Res. 56, 7375-7383.

29 Jaubert J.N., Avaullee L., Pierre C. (2002) Is it still necessary to measure the minimum miscibility pressure? Indus. Eng. Chem. Res. 41, 2, 303-310.

30 Avaullée L., Duchet-Suchaux P., Durandeau M., Jaubert J. N. (2001) A new approach in correlating the oil thermodynamic properties, J. Petrol. Sci. Eng. 30, 1, 43-65.

31 Wu Sh., He J., Li Z.Zh., Lin W.M., Wang Q.T., Wu F.Y., Zhao B., Zhang J.J. (2015) Studies on the chemical agent system for reducing in the minimal miscibility pressure of $\mathrm{CO}_{2}$ flooding, China Sciencepaper 10, 18, 2161-2164.

32 Jing L.Sh. (2014) Solubility of nonionic surfactants used in $\mathrm{CO}_{2}$ miscible flooding, Master Thesis, Dalian University of Technology.

33 Guo P., Jiao S.J., Chen F., He J., Li Y.Q., Zeng H. (2012) Optimization and oil displacement efficiency of non-ionic low molecular surfactant, Oil Drill. Prod. Technol. 34, 2, 81-84.

34 Zhang G.D., Liu J.Y., Liu Y.L., Zhou F. (2013) Study on reducing miscibility pressure in $\mathrm{CO}_{2}$ flooding by miscible solvent, Special Oil Gas Reserv. 20, 2, 115-117.

35 Peng Ch., Liu J.Y., Zhang G.D., Peng Y.J., Guo K. (2012) A new method of reducing the miscible-phase pressure of $\mathrm{CO}_{2}$ flooding, Journal of Chongqing University of Science and Technology (Natural Science edition) 14, 1, 48-51.

36 Harrison K., Goveas J., Johnston K.P., O'Rear E.A. (1994) Water-in-carbon dioxide microemulsions with a fluorocarbonhydrocarbon hybrid surfactant, Langmuir 10, 10, 3536-3541.

37 Eastoe J., Gold S. (2005) Self-assembly in green solvents, Phys. Chem. Chem. Phys. 7, 7, 1352-1362. 
38 Rocha S.R.P.D., Dickson J., Cho D., Rossky P.J., Johnston K.P. (2003) Stubby surfactants for stabilization of water and CO2 emulsions: trisiloxanes, Langmuir 19, 8, 3114-3120.

39 Fink R., Hancu D., Valentine R., Beckman E.J. (1999) Toward the development of " $\mathrm{CO}_{2}$-philic" hydrocarbons. 1. Use of side-chain functionalization to lower the miscibility pressure of polydimethylsiloxanes in $\mathrm{CO}_{2}$, J. Phys. Chem. B 103, 31, 6441-6444.

40 Zhang T.Y., Zhong L. (2005) Surfactants for supercritical $\mathrm{CO}_{2}$, Chem. Bull. 68, 8, 585-590.

41 Hoefling T., Stofesky D., Reid M., Beckman E., Enick R.M. (1992) The incorporation of a fluorinated ether functionality into a polymer or surfactant to enhance $\mathrm{CO}_{2}$-solubility, $J$. Supercrit. Fluids 5, 4, 237-241.

42 DeSimone J.M., Keiper J.S. (2001) Surfactants and selfassembly in carbon dioxide, Curr. Opin. Solid State Mater. Sci. 5, 4, 333-341.

43 Lou D.L., Xu B.Ch., Qiu T.Q. (2013, 1861,) Comparison and dynamic models of supercritical $\mathrm{CO}_{2}$ extraction enhanced by different technologies, Modern Food Sci. Technol. 029, 008, 1921-1925.

44 Dong Zh.X., Cui B., Li Y., Lin M.Q., Li M.Y. (2013) MMP of supercritical carbon dioxide microemulsion and alkanes, $J$. Petrochem. Univ. 26, 1, 40-44.

45 Dong Zh.X., Li Y., Lin M.Q., Li M.Y. (2013) A study of the mechanism of enhancing oil recovery using supercritical carbon dioxide microemulsions, Petrol. Sci. 10, 1, 91-96.

46 Song Zh.J., Li Zh.P., Yu Ch.Sh. (2014) D-optimal design for rapid assessment model of $\mathrm{CO}_{2}$ flooding in high water cut oil reservoirs, J. Nat. Gas Sci. Eng. 21, 11, 764-771.

47 Han H.Sh., Li Sh., Chen X.L. (2016) Main control factors of carbon dioxide on swelling effect of crude hydrocarbon components, Acta Petrolei Sinica 37, 3, 392-398.

48 Yang Zh.M., Liu X.W., Zhang Zh.H. (2015) Physical simulation of staged-fracturing horizontal wells using $\mathrm{CO}_{2}$ huff and puff in tight oil reservoirs, Acta Petrolei Sinica 36, 6, 724-729.

49 Chen F., He J., Guo P. (2012) A method used for reducing the minimum miscible pressure between oil and $\mathrm{CO}_{2}$ in miscible flooding, Chinese Patent 102337874A 2.

50 Choubineh A., Mousavi S.R., Ayouri M.V., Ahmadinia M., Choubineh D., Baghban A. (2016) Estimation of the $\mathrm{CO}_{2}$-oil minimum miscibility pressure for enhanced oil recovery, Petrol. Sci. Technol. 34, 22, 1847-1854.

51 Li D., Li X.L., Zhang Y.H., Sun L.X., Yuan Sh.L. (2019) Four methods to estimate minimum miscibility pressure of $\mathrm{CO}_{2}$-oil based on machine learning, Chin. J. Chem. 37, 1271-1278.

52 Ebrahimi A., Khamehchi E. (2014) The use of optimization procedures to estimate minimum miscibility pressure, Petrol. Sci. Technol. 32, 8, 947-957.

53 Rahimi V., Bidarigh M., Bahrami P. (2017) Experimental study and performance investigation of miscible wateralternating- $\mathrm{CO}_{2}$ flooding for enhancing oil recovery in the
Sarvak formation, Oil Gas Sci. Technol. - Rev. IFP Energies nouvelles 72, 35. https://doi.org/10.2516/ogst/2017030.

54 Luo E.H., Fan Z.F., Hu Y.L., Zhao L., Wang J.J. (2019) An evaluation on mechanisms of miscibility development in acid gas injection for volatile oil reservoirs, Oil Gas Sci. Technol. Rev. IFP Energies nouvelles 74, 59. https://doi.org/ $10.2516 /$ ogst $/ 2019018$.

55 Jaubert J.N., Borg P., Coniglio L., Barth D. (2001) Phase equilibria measurements and modeling of EPA and DHA ethyl esters in supercritical carbon dioxide, J. Supercrit. Fluids 20, 2, 145-155. https://doi.org/10.1016/S0896-8446 (01)00062-6.

56 Jaubert J.N., Coniglio L., Denet F. (1999) From the Correlation of Binary Systems Involving Supercritical $\mathrm{CO}_{2}$ and Fatty Acid Esters to the Prediction of $\left(\mathrm{CO}_{2}-\right.$ Fish Oils $)$ Phase Behavior, Indus. Eng. Chem. Res. 38, 8, 3162-3171. https://doi.org/10.1021/ie9807831.

57 Delforouz F.B., Movaghar M.R.K., Shariaty S. (2019) New empirical correlations for predicting Minimum Miscibility Pressure (MMP) during $\mathrm{CO}_{2}$ injection; implementing the Group Method of Data Handling (GMDH) algorithm and Pitzer's acentric factor, Oil Gas Sci. Technol. - Rev. IFP Energies nouvelles 74, 64. https://doi.org/10.2516/ogst/ 2019035.

58 Abdurrahman M., Bae W., Permadi A.K. (2019) Determination and evaluation of minimum miscibility pressure using various methods: experimental, visual observation, and simulation, Oil Gas Sci. Technol. - Rev. IFP Energies nouvelles 74, 55. https://doi.org/10.2516/ogst/2019028.

59 Nichita D.V., Broseta D., Montel F. (2019) Application of near critical behavior of equilibrium ratios to phase equilibrium calculations, Oil Gas Sci. Technol. - Rev. IFP Energies nouvelles 74, 77. https://doi.org/10.2516/ogst/2019049.

60 Berneti S.M., Varaki M.A. (2018) Development of $\varepsilon$-insensitive smooth support vector regression for predicting minimum miscibility pressure in $\mathrm{CO}_{2}$ flooding, Songklanakarin J. Sci. Technol. 40, 1, 53-59.

61 Zhang A.G., Fan Z.F., Zhao L., Xu A.Zh. (2020) An evaluation on phase behaviors of gas condensate reservoir in cyclic gas injection, Oil Gas Sci. Technol. - Rev. IFP Energies nouvelles $\mathbf{7 5}, 4$. https://doi.org/10.2516/ogst/ 2019070.

62 He C.G., Mu L.X., Xu A.Zh., Zhao L., He J., Zhang A.G., Shan F.Ch., Luo E.H. (2019) Phase behavior and miscible mechanism in the displacement of crude oil with associated sour gas, Oil \& Gas Science and Technology - Rev. IFP Energies nouvelles 74, 54. https://doi.org/10.2516/ogst/ 2019024.

63 Fathinasab M., Ayatollahi S., Taghikhani V., Shokouh S.P. (2018) Minimum miscibility pressure and interfacial tension measurements for $\mathrm{N}_{2}$ and $\mathrm{CO}_{2}$ gases in contact with $\mathrm{W} / \mathrm{O}$ emulsions for different temperatures and pressures, Fuel $\mathbf{2 2 5}$, 623-631. https://doi.org/10.1016/j.fuel.2018.03.134. 